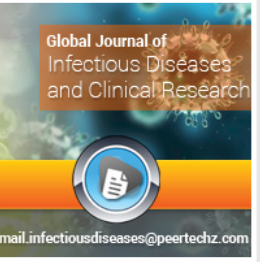

\title{
Global Journal of Infectious Diseases and Clinical Research
}

Hoan Tran Thanh, Dung Tran Trung*, Thanh Ma Ngoc, Minh Ho Ngoc, Hung Pham Xuan, Tung Tran Son, Ban Hoang Van, Trinh Le Khanh and Phong Nguyen Duc

Hanoi Medical University, Ton That Tung Street, Hanoi, Vietnam

Dates: Received: 10 November, 2017; Accepted: 20 November, 2017; Published: 21 November, 2017

*Corresponding author: Dung Trung Tran, MD, $\mathrm{PhD}$, Associate Professor, Hanoi Medical University, No 1, Ton That Tung Street, Hanoi, Vietnam, Tel: +84-24-238523798; Fax: +86-24- 38523798; E-mail: dungbacsy@dungbacsy.com

Keywords: Infected osteoarthritis of knee; Knee arthroscopy

https://www.peertechz.com
Research Article

Arthroscopic treatment for Intraarticular knee infection in Hanoi Medical University Hospital

\section{Summary}

Objectives: 1) Describe the arthroscopic image of infected osteoarthritis of knee; 2) Evaluate the result of arthroscopic treatment for infected osteoarthritis of knee

Patients and method: Retrospective study 33 patients underwent arthroscopic treatment for infected osteoarthritis of knee in Hanoi Medical University Hospital from 2009 to 2013

Results: $1^{\text {st }}$ stage of osteoarthritis occupied $36.4 \% ; 45.5 \%, 12.1 \%$ and $6 \%$ for $2^{\text {nd }}, 3^{\text {rd }}$ and $4^{\text {th }}$ respectively. According to Bussier classification, the excellent and good result is $72.7 \%$; moderate is $21.2 \%$ and bad result is $6.1 \%$.

Conclusion: Arthroscopic treatment for infected osteoarthritis of knee give good result.

\section{Background}

Septic arthritis results from infection by non-specific microorganisms [1]. Accounting for one half of the total cases of joint infection in general, septic knee arthritis is a complicated lesions with possible functional results. One can completely recover from this disease in condition of early diagnosis and effective treatment.

Infectious knee arthritis has various aetiologies, probably resulting from infected hematoma or other medical conditions like osteoarthritis and Gout. The abuse of intra-articular procedures in today's practice like acupuncture, intraarticular injection or arthrocentesis is becoming more common with reduced time for each. The fact that sterile principles, procedure instructions and indications are not strictly followed by physicians puts patients under increasingly higher risk of infection, which raises the problem of knee joint infection in Vietnam more severely.

One of treatment principles is articular debridement and pus drainage. Arthroscopy with aid of magnifying camera provides a minimally invasive way into intra-articular space but a wide range of assessment, therefore, one can simultaneously repair infected lesions and other articular comorbidities. In Vietnam, arthroscopy has been widely applied into practice of diagnosis and treatment of septic knee arthritis since 2002.
This study was conducted with two main aims:

1. To describe arthroscopic images of infectious knee arthritis.

2. To evaluate results of treatment of infectious knee arthritis with arthroscopy.

\section{Patients and method}

This is a retrospective study. The patients diagnosed intraarticular knee infection and were operated under arthroscopy at Hanoi Medical University during the period from January 2009 to June 2013 were included in this study if satisfied the following criteria.

\section{Inclusion criteria:}

- Patients are diagnosed with intraarticular knee infection.

- Get a knee arthroscopy.

- Has evidence of bacteria in the joint.

- Medical record are complete.

\section{Exclusion criteria:}

- Acute non-infectious inflammation.

- Medical record are not complete. 
The intraarticular infection was classified according to Gächter criteria with 4 stages [2-4]:

Stage I: Opacity of fluid, redness of the synovial membrane.

Stage II: Severe inflammation, fibrinous deposition, pus.

Stage III: Thickening of the synovial membrane, compartment formation ("sponge-like" arthroscopic view, especially in the supra-patellar pouch).

Stage IV: Aggressive pannus with infiltration of the cartilage, possibly undermining the cartilage, radiological signs of subchondral osteolysis, possible osseous erosions and cysts.

Evaluate the results of treatment when patient discharges according to Bussière criteria as follows [5]:

- Excellent: no pain, full range of motion, no sign of recurrence at the time of follow-up.

- Good: occasional mild pain slight reduction of movement, no sign of recurrence at the time of followup.

- Fair: frequent moderate pain, occasional joint effusion, limited range of motion with flexion $<120$ or flexion contracture $<10$

- Poor: permanent severe pain, permanent joint effusion, more limited range of motion with flexion $<90$ and flexion contracture $>10$.

The collected data is processed by computer algorithm using SPSS Statistic 16.0 software.

\section{Results}

33 patients (19 men (57.6\%), 14 women (42.4\%) with intraarticular knee infection were treated with knee arthroscopy.

The average age of the patients was $46.2 \pm 15.9$ (ranging from 13-81) years. The 40-49 age group occupied the largest proportion of $30.3 \%$. Most of the patients were over 40 years old $(69.6 \%)$. Patients over age 60 accounted for $21.2 \%$.

Stages I and II were presented in $81.9 \%$ of all the patients. Stage II took up the largest proportion $(45.5 \%)$, followed by stage I (36.4\%), stage III (12.1\%), and stage IV (6.0\%) (Table 1$)$

The excellent and good results occupied $72.7 \%$. The poor result is $6.1 \%$ (Table 2 ).

In the stage I group, good and excellent functional result were present by 12/12 cases. In the stage II group, 15/15 cases showed at least fair functional result ( $66.7 \%$ good and excellent, $33.3 \%$ fair). In the stage III group, $2 / 4$ cases $(50 \%)$ presented with good and excellent result, followed by fair (25\%) and poor $(25 \%)$. In the stage IV group with 2 patients, the percentage of fair and poor result are $50 \%$ each.
Table 1: Results of treatment according to the Functional evaluation of Bussière

\begin{tabular}{|c|c|c|}
\hline \multirow{2}{*}{ Results of treatment } & \multicolumn{2}{|c|}{ Total } \\
\cline { 2 - 3 } & Number of patients & $\%$ \\
\hline Excellent & $\mathbf{5}$ & 15.1 \\
\hline Good & 19 & 57.6 \\
\hline Fair & 7 & 21.2 \\
\hline Poor & 2 & 6.1 \\
\hline Total & $\mathbf{3 3}$ & $\mathbf{1 0 0}$ \\
\hline
\end{tabular}

Table 2: Distribution of Results of treatment according to Gächter arthroscopic classification.

\begin{tabular}{|c|c|c|c|c|c|c|}
\hline \multirow{2}{*}{ Results of treatment } & \multicolumn{4}{|c|}{ Stages } & \multirow{2}{*}{ Total } & \multirow{2}{*}{$\mathbf{p}$} \\
\hline & I & II & III & IV & & \\
\hline Excellent & 3 & 1 & 1 & 0 & 5 & \multirow{4}{*}{$<0.05$} \\
\hline Good & 9 & 9 & 1 & 0 & 19 & \\
\hline Fair & 0 & 5 & 1 & 1 & 7 & \\
\hline Poor & 0 & 0 & 1 & 1 & 2 & \\
\hline Total & 12 & 15 & 4 & 2 & 33 & \\
\hline
\end{tabular}

There was a statistically significant correlation between the Gatcher score and the treatment results, in which patients in later stages showed a poorer outcome $(\mathrm{p}<0.05)$.

According to the Functional evaluation of Bussière, Good and Excellent functional result were present by $15.1 \%$ and $57.6 \%$ of all cases, respectively. Only $6.1 \%$ patients showed Poor functional result.

\section{Discussion}

Our study sample consisted of 33 patients with a mean age of 46.2 years, ranging from 13 to 81 years. In particular, the most common age group was from 40 to 49 , accounting for $30.3 \%$. Our findings was similar to the results of other authors, such as Bussière $\mathrm{F}$ [5], (mean: 52 years, 95CI 18-93), Balabaud L [2], (mean: 49 years, 95CI 19-81). In our study, the majority of patients were aged from 20 to 60 years, comprising $72.7 \%$ totally. This is the main working age group so if there is sequelae in the knee it will greatly affect the work capacity of patients after treatment. This also will considerably affect the quality of life of patients as well as their family and society. The age group under 20 years of age in this study was only found at $6.1 \%$. Age group over 60 years old accounted for $21.2 \%$. Russels and Amsell [6], found that $25-30 \%$ of cases of septic arthritis were aged over 60 years. Regarding to gender, Nade $\mathrm{S}$ [7], found that the prevalence of men were slightly higher than women. The male/female ratio in the study of Bussière $F$ [5],is $12 / 4=3 / 1$. In our study, the male/female ratio was $19 / 14=1.4$, male ratio was slightly higher than female.

According to Gächter's classification, in our study, $81.9 \%$ of patients had infection in the arthroscopy stage I, II while the proportion of patients with stage II was the largest (45.5\%). stage I accounted for $36.4 \%$, stage III and IV were $12.1 \%$ and $6.0 \%$ respectively (Chart 1 ). The numbers of patients between different stages were statistically significant $(p<0.05)$. Thus, in our study, a significant proportion of patients had arthritis in stage III and IV. This is the stage where joint had been damaged severely. Ineffective treatment for a long time in 


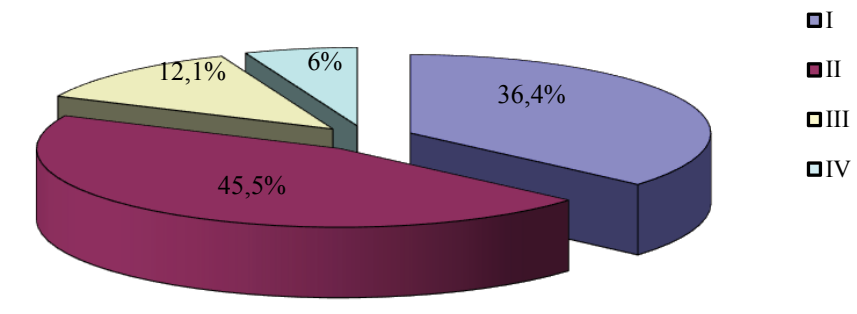

Chart 1: Stages according to Gächter arthroscopic classification.

other hospitals is the biggest problem of our patients, which limits probability of recovery. Therefore, antibiotics therapy no longer can suppress further articular deterioration. In the study by Stutz G [3], $28.2 \%$ of all patients suffered from stage I, while stage II and III covered $56.4 \%$ and $15.4 \%$ respectively, with which our results were consistent.

According to functional scale of Bussière, $72.7 \%$ patients experienced Excellent and Good outcomes (15.1\% and 57.6\%, respectively), $21.2 \%$ referred their treatment to Fair effects and only $6.1 \%$ reported Poor results. In the study conducted by Tsumura $\mathrm{H}$ [8], 9 out of 11 (81.8\%) patients suffering from knee infection treated with medications and arthroscopy had good final outcomes. Bussière $F$ [5], studied post-treatment results of combined therapy between medications and arthroscopy in fourteen cases of septic knee arthritis: $42.9 \%, 50 \%$ and $7.1 \%$ for Excellent, Good and Poor respectively. Stutz G [3], concluded that the frequency of arthroscopy carried out depended on the response to treatment of patients, ranging from one to four times. Combined therapy with medications could be successful in $91 \%$ of all 78 cases and this rate was inversely proportional to arthrocopic stages of Gächter's classification: $96 \%, 95 \%$ and $67 \%$, respectively, at stage I, II and III. Other authors agreed that combining medications with arthroscopy was an effective treatment for pyogenic knee arthritis. In cases with slow symptomatic improvement, arthroscopy could be repetitively performed to achieve expected results. Re-arthroscopy was related to the initial stage of injury. Vispo Seara JL [4], studied 40 cases of septic knee arthritis to obtain the results: $30 \%$ for Excellent and Good, $20 \%$ for Fair and Poor, separately. He noted that outcomes of infectious knee arthritis have a correlation with age, delay before surgery and pre-arthroscopic severity of knee joint injury.

We discovered that final results of treatment of pyogenic knee arthritis was associated with arthroscopic stages of lesions.
The rate of Excellent and Good outcomes in early stages (I and II) was higher than in the late ones (III and IV) $(\mathrm{p}<0.05)$. Our findings were consistent with other authors' results. According to Stutz G [3], the successful rate of combined therapy in septic knee arthritis was $91 \%$ generally and decreased at later stages with $96 \%$ and $95 \%$ at stage I and II respectively but $67 \%$ at stage III.

\section{Conclusion}

With the study of arthroscopy in 33 patients having infectious knee arthritis, we came to our conclusions as following:

According to Gächter's classification, in our study, grade I: $36.4 \%$, grade II: $45.5 \%$, grade III: $12.1 \%$ and grade IV: $6.0 \%$.

Results of treatment of septic knee arthritis by arthroscopy combined with medications: Excellent and Good outcome $72.7 \%$ (15.1\% and $57.6 \%$ respectively); Fair outcome: $21.2 \%$; Poor outcome: $6.1 \%$.

\section{References}

1. Brause BD (2000) "Infectious arthritis", Manual of Rheumatology and Outpatient Orthopedic Disorders: Diagnosis and Therapy, $4^{\text {th }}$ edition, Lippincott William \& Wilkins, $307-312$

2. Balabaud L, Gaudias J, Boeri C, Jenny JY, Kehr P (2007) Result of treatment of septic knee arthritis: a retrospective series of 40 cases, Knee Surg Sports Traumatol Arthrosc 15: 387-392. Link: https://goo.gl/6i6nEv

3. Stutz G, Kuster MS, Kleinstück F, Gächter A (2000) Arthroscopic management of septic arthritis: stages of infection and results. Knee Surg Sports Traumato Arthrosc 8: 270 - 274. Link: https://goo.gl/daJSd1

4. Vispo Seara JL, Barthel T, Schmitz H, Eulert J (2002) Arthroscopic treatment of septic joints: prognostic factors. Arch Orthop Trauma Surg, 122: 204 211. Link: https://goo.gl/8h2awx

5. Bussière $F$, Beaufils $P$ (1999) Role of arthroscopy in the treatment of pyogenic arthritis of the knee in adults. Report of 16 cases. Rev Chir Orthop Reparatrice Appar Mot 85: 803-810. Link: https://goo.gl/5fxLDr

6. Russell AS, Ansell BM (1972) Septic arthritis, Annals of the Rheumatic Diseases 31: 40 - 44. Link: https://goo.gl/QCbSy8

7. Nade S (2003) Septic arthritis Best Practice \& Research Clinical Rheumatology 17: 183 - 200. Link: https://goo.gl/dRquqV

8. Tsumura H, Ikeda S, Torisu T (2005) Debridement and continuous irrigation for the treatment of pyogenic arthritis caused by the use of intra-articular injection in the osteoarthritic knee: indications and outcomes. J Orthop Surg (Hong Kong) 13: 52 - 57. Link: https://goo.gl/ykxWpz 